\title{
Does developmental prosopagnosia impair identification of other-ethnicity faces?
}

\section{Article}

\section{Accepted Version}

Creative Commons: Attribution-Noncommercial-No Derivative Works 4.0

Cenac, Z., Biotti, F., Gray, K. L. H. and Cook, R. (2019) Does developmental prosopagnosia impair identification of otherethnicity faces? Cortex, 119. pp. 12-19. ISSN 0010-9452 doi: https://doi.org/10.1016/j.cortex.2019.04.007 Available at https://centaur.reading.ac.uk/83175/

It is advisable to refer to the publisher's version if you intend to cite from the work. See Guidance on citing.

To link to this article DOI: http://dx.doi.org/10.1016/j.cortex.2019.04.007

Publisher: Elsevier

All outputs in CentAUR are protected by Intellectual Property Rights law, including copyright law. Copyright and IPR is retained by the creators or other copyright holders. Terms and conditions for use of this material are defined in the End User Agreement.

\section{www.reading.ac.uk/centaur}

\section{CentAUR}

Central Archive at the University of Reading

Reading's research outputs online 
In press at: Cortex

Format: Research Report

Word count: 3993

Running Head: Perception of other-ethnicity faces in developmental prosopagnosia

Does developmental prosopagnosia impair identification of other-ethnicity faces?

\author{
Zarus Cenac ${ }^{1}$, Federica Biotti ${ }^{2}$, Katie L.H. Gray ${ }^{3}$, \& Richard Cook ${ }^{4 *}$ \\ ${ }^{1}$ Department of Psychology, \\ City, University of London, London, U.K. \\ ${ }^{2}$ Department of Psychology, \\ Royal Holloway, University of London, Egham, U.K. \\ ${ }^{3}$ School of Psychology and Clinical Language Sciences, \\ University of Reading, Reading, U.K. \\ ${ }^{4}$ Department of Psychological Sciences, \\ Birkbeck, University of London, London, U.K.
}

*Corresponding author:

richard.cook@bbk.ac.uk

Department of Psychological Sciences,

Birkbeck, University of London,

London, U.K.

WC1E 7HX 


\section{Highlights}

- Caucasian DPs and controls judged whether pairs of faces were identical or not

- As expected, the DPs exhibited poor discrimination of same-ethnicity faces

- Relative to controls, the DPs also exhibited impairment when judging Black faces

- We found no evidence of disproportionate impairment for same-ethnicity faces

- Both groups described similar levels of experience with other-ethnicity faces 


\begin{abstract}
Current approaches to the diagnosis of developmental prosopagnosia emphasise the perception and identification of same-ethnicity faces. This convention ensures that perceptual impairment arising from developmental prosopagnosia can be distinguished from problems arising from a lack of visual experience with particular facial ethnicities - the so-called 'Other-Ethnicity Effect'. The present study sought to determine whether the perceptual difficulties seen in developmental prosopagnosia - diagnosed using same-ethnicity faces extend to other-ethnicity faces. First, we sought to determine whether a group of Caucasian developmental prosopagnosics $(\mathrm{N}=15)$ and typical Caucasian controls $(\mathrm{N}=30)$ had similar experience with same- and other-ethnicity faces during development. All participants therefore completed a contact questionnaire that enquired about their experience of Caucasian, Black, and East Asian faces, at different developmental stages. Importantly, the two groups described very similar levels of visual experience with other-ethnicity faces. Second, we administered a sequential matching task to measure participants' ability to discriminate same- (Caucasian) and other-ethnicity (Black, East Asian) faces. Relative to the experience-matched controls, the prosopagnosics were less accurate at discriminating both same- and other-ethnicity faces, and we found no evidence of disproportionate impairment for same-ethnicity faces. Given that the prosopagnosics and controls had similar opportunity to develop visual expertise for other-ethnicity faces, these results indicate that developmental prosopagnosia impairs recognition of both same- and other-ethnicity faces. The fact that developmental prosopagnosia affects the perception of both same- and other-ethnicity faces suggests that different facial ethnicities engage similar visual processing mechanisms. Our findings support the view that susceptibility to developmental prosopagnosia, and a lack of contact with other-ethnicity faces, contribute independently to the poor recognition of otherethnicity faces.
\end{abstract}

\title{
Key words:
}

Developmental prosopagnosia, face recognition, other-ethnicity faces, visual experience 


\section{Introduction}

Developmental prosopagnosia $^{1}$ (DP) is a neurodevelopmental condition associated with difficulties recognising familiar faces and distinguishing unfamiliar faces, that occurs in people with normal intelligence and typical visual acuity, and in the absence of manifest brain injury (Behrmann \& Avidan, 2005; Duchaine \& Nakayama, 2006b; Susilo \& Duchaine, 2013). DP often runs in families indicating that the condition may have a genetic component (Duchaine, Germine, \& Nakayama, 2007; Johnen et al., 2014; Schmalzl, Palermo, \& Coltheart, 2008). Individuals with DP identify others using non-face cues (e.g., hairstyle, voice, and gait) and often experience great difficulty when familiar people are met in unusual contexts or when they alter their appearance (Cook \& Biotti, 2016; Shah, Gaule, Sowden, Bird, \& Cook, 2015). Historically, the condition was thought to be rare (McConachie, 1976), but current estimates suggest that $2 \%$ of the general population may experience face recognition difficulties severe enough to disrupt their daily lives (Kennerknecht et al., 2006; Kennerknecht, Ho, \& Wong, 2008).

Current approaches to the diagnosis of DP emphasise the perception and identification of same-ethnicity (SE) faces; for example, when testing Caucasian and East Asian individuals for DP, researchers typically administer standardised tests that measure the identification of Caucasian (Duchaine \& Nakayama, 2006a) and East Asian (McKone, Wan, Robbins, Crookes, \& Liu, 2017) faces, respectively. There is good reason for this convention. Poor recognition of other-ethnicity $(\mathrm{OE})$ faces can arise from a lack of visual experience during development - the 'Other-Ethnicity Effect' (OEE; Sangrigoli, Pallier, Argenti, Ventureyra, \& de Schonen, 2005; Tanaka, Heptonstall, \& Hagen, 2013; Wan, Crookes, Reynolds, Irons, $\&$ McKone, 2015), and does not necessarily reveal the presence of a hereditary neurodevelopmental disorder. Below-average scores on tests of $\mathrm{OE}$ face recognition therefore provide equivocal diagnostic evidence for DP.

The aim of the present study was to determine whether the perceptual difficulties seen in DP - diagnosed using SE faces - extend to OE faces. While the use of OE faces in the diagnosis of DP is discouraged (e.g., Bowles et al., 2009; Dalrymple \& Palermo, 2016; McKone et al., 2017), it is theoretically important to determine whether DPs are impaired at OE face recognition, relative to typical observers matched for visual experience with OE faces. In particular, evidence of selective impairment for SE faces would indicate that the mechanisms recruited by OE and SE faces dissociate (also see Jaquet, Rhodes, \& Hayward, 2008; Michel, 
Rossion, Han, Chung, \& Caldara, 2006; Tanaka, Kiefer, \& Bukach, 2004; Wiese, Kaufmann, $\&$ Schweinberger, 2014). Revealing the breadth of the perceptual impairments in DP also provides important insights into the neurocognitive origins of the condition (Biotti \& Cook, 2016; Biotti, Gray, \& Cook, 2017; Geskin \& Behrmann, 2017); for example, evidence of typical recognition of $\mathrm{OE}$ faces would argue against domain-general accounts of the condition (Avidan, Tanzer, \& Behrmann, 2011; Gerlach, Klargaard, Petersen, \& Starrfelt, 2017).

In the typical population, poor recognition performance for SE faces is associated with poor recognition performance for OE faces (DeGutis, Mercado, Wilmer, \& Rosenblatt, 2013; Wan et al., 2017). However, surprisingly few authors have examined the perception of OE faces in observers with DP. One exception is a study described by DeGutis, DeNicola, Zink, McGinchley and Milberg (2011). Using a paradigm designed to measure the Part-Whole Effect (Tanaka \& Farah, 1993), the authors found that five Caucasian DPs were worse than Caucasian controls at matching Korean faces that differed by a single feature (eyes, nose, or mouth). A week later, however, the DPs completed the same task again, after a short training procedure with Caucasian face stimuli. This time, the ability of the controls and the DPs to discriminate Korean faces was almost identical. Interpretation of this result is further complicated by the fact that the DPs and the typical controls were not matched in terms of their experience with East Asian faces. In a related study, Esins, Schultz, Wallraven and Bulthoff (2014) found that 21 Caucasian DPs were less accurate than a sample of typical Korean observers at recognising and sorting Caucasian faces. While this second study suggests that the OEE and DP have different origins - for example, the deficits associated with DP may be more severe than those associated with the OEE - it does not indicate whether DPs have perceptual difficulties with OE faces.

Some accounts of DP clearly predict impaired perception of OE faces, relative to experiencematched controls. For example, it has been argued that delayed or impoverished processing of global shape information produces a wide range of visual deficits in DP, including face and non-face object recognition difficulties (Avidan et al., 2011; Gerlach et al., 2017; Tanzer, Freud, Ganel, \& Avidan, 2013). Provided both groups have equal opportunities to develop perceptual expertise, this account predicts that DPs should exhibit poorer recognition of OE faces relative to controls. 
Other accounts of DP suggest that these individuals may be unimpaired at OE face recognition. For example, it has been suggested that the face recognition difficulties in DP arise from a domain-specific deficit of holistic face processing that prevents the integration of facial features into a unified whole (DeGutis, Cohan, \& Nakayama, 2014; Palermo, Willis, et al., 2011; Rossion, 2013). If OE faces are subject to piecemeal rather than holistic processing (Michel et al., 2006; Tanaka et al., 2004), OE faces may not tax the perceptual mechanisms that are impaired in DP. Consequently, DPs and experience-matched controls might show similar levels of OE face recognition.

\section{Research transparency and openness}

Neither the study procedure nor the intended analyses were pre-registered prior to the start of the research. In the following sections we report how we determined our sample size, all data exclusions, all inclusion criteria, and whether inclusion/exclusion criteria were established prior to data analysis. All manipulations and all measures in the study are reported. All study materials, including the stimuli and experimental program, are available through the Open Science Framework (https://osf.io/yck8s/). The questionnaire data (raw responses and summary measures) are provided as supplementary online material. Summary data for the discrimination task are provided as supplementary online material and the raw data files are available through the Open Science Framework (https://osf.io/yck8s/). Ethical approval was granted by the local ethics committee. The research was conducted in line with the ethical guidelines provided by the 6th (2008) Declaration of Helsinki.

\section{Participants}

Fifteen Caucasian DPs (5 males, $M_{\text {age }}=40.87$ years, $S D_{\text {age }}=9.76$ years $)$ and 30 typically developed (TD) Caucasian controls (14 males, $M_{\text {age }}=38.77$ years, $S D_{\text {age }}=13.34$ years) participated in the experiment. The groups did not differ with respect to mean age $[t(43)=$ $.540, p=.592]$, nor proportion of males $\left[X^{2}(1)=.28, p=.597\right]$. In order to participate in the study, individuals were required to be aged 18 to 65 years-old and have normal or correctedto-normal visual acuity (inclusion criteria determined at outset of study). Sample size was determined a-priori based on similar group studies of DP (e.g., Biotti \& Cook, 2016; Biotti et al., 2017; Shah, Gaule, Gaigg, Bird, \& Cook, 2015). All typical controls scored less than 65 when screened for DP using the Twenty-Item Prosopagnosia Index (PI20; Gray, Bird, \& Cook, 2017; Shah, Gaule, Sowden, et al., 2015). All participants were tested in person under 
controlled lab conditions. All participants provided informed consent and were fully debriefed after the experimental procedure.

DP participants were recruited through $\underline{w w w . t r o u b l e w i t h f a c e s . o r g}$ and reported lifelong face recognition difficulties in the absence of brain injury and psychiatric disorder (e.g., autism or schizophrenia). Diagnostic information for each DP is provided in Table 1. Diagnostic decisions were based primarily on participants' scores on the Cambridge Face Memory Test (CFMT; Duchaine \& Nakayama, 2006a) and the PI20. We also provide individuals' scores on the Cambridge Face Perception Test (CFPT; Duchaine et al., 2007) to index the relative severity of their perceptual encoding difficulties. The use of convergent self-report evidence and scores on objective, computer-based tasks may be a particularly effective approach to the identification and classification of DP; for example, less than $1.5 \%$ of the general population score below $65 \%$ on the CFMT and more than 65 on the PI20 (Gray et al., 2017).

\section{Table-1}

\section{Experience of other-ethnicity faces}

First, we sought to determine whether the two groups (DPs, TDs) were equated for experience with SE and OE faces. Visual experience of Caucasian, Black, and East Asian faces was measured using an Inter-Ethnicity Contact Questionnaire (IECQ) ${ }^{2}$. The questionnaire comprised the following 6 items: i) Most days, I encountered peers with (ethnicity) faces in educational or social contexts; ii) In my local community, many people were (ethnicity); iii) Most days, I had face-to-face interactions with (ethnicity) people; iv) I saw many (ethnicity) individuals in TV shows, films, and online videos; v) I saw many (ethnicity) individuals in printed media (e.g., newspapers, magazines, books); vi) Many of the characters depicted in the advertising materials I was exposed were (ethnicity). Participants were asked to rate the strength of their agreement with each statement using a 7-point Likert scale $(1=$ disagree strongly; 7 agree strongly). The visual system may show greater plasticity during some developmental stages, relative to others; for example, exposure to a particular face type during a 'critical period' may facilitate the development of perceptual expertise (e.g., Geldart, Mondloch, Maurer, De Schonen, \& Brent, 2002). Participants therefore completed the IECQ for three life stages: 0-6, 6-12, and 12-18 years-of-age (also see Cloutier, Li, \& Correll, 2014). The subscales assessing contact with Caucasian 
$($ Cronbach's alpha $=.80)$, Black $($ Cronbach's alpha $=.78)$, and East Asian individuals (Cronbach's alpha $=.82)$ showed good internal reliability.

Participants' IECQ responses (Figure 1) were analysed using ANOVA with Face Type (Caucasian, Black, East Asian) as a within-subjects factor, and Group (DP, TD) as a betweensubjects factor. As expected, a main effect of Face Type was seen at 0-6 years $[F(2,86)=$ $\left.574.714, p<.001, \eta_{\mathrm{p}}{ }^{2}=.930\right], 6-12$ years $\left[F(2,86)=435.256, p<.001, \eta_{\mathrm{p}}{ }^{2}=.910\right]$, and 1218 years $\left[F(2,86)=296.365, p<.001, \eta_{\mathrm{p}}{ }^{2}=.873\right]$, whereby DP and TD participants had more experience with Caucasian faces than Black and Asian faces. However, there was no main effect of Group at 0-6 years $\left[F(1,43)=.195, p=.661, \eta_{\mathrm{p}}{ }^{2}=.005\right], 6-12$ years $[F(1,43)$ $\left.=.140, p=.710, \eta_{\mathrm{p}}{ }^{2}=.003\right]$, or 12-18 years $\left[F(1,43)=.142, p=.708, \eta_{\mathrm{p}}{ }^{2}=.003\right]$. Most importantly, we saw no Group $\times$ Face Type interaction at any of the life stages: 0-6 years $\left[F(2,86)=.167, p=.846, \eta_{\mathrm{p}}^{2}=.004\right], 6-12$ years $\left[F(2,86)=.948, p=.391, \eta_{\mathrm{p}}^{2}=.022\right]$, or $12-18$ years $\left[F(2,86)=.347, p=.708, \eta_{\mathrm{p}}{ }^{2}=.008\right]$. Analysis of the combined IECQ data (collapsing across life-stage) revealed a main effect of Face Type $[F(2,86)=494.062, p<$ $\left..001, \eta_{\mathrm{p}}^{2}=.920\right]$, but no main effect of Group $\left[F(1,43)=.023, p=.881, \eta_{\mathrm{p}}{ }^{2}=.001\right]$, nor a Face Type $\times$ Group interaction $\left[F(2,86)=.444, p=.643, \eta_{\mathrm{p}}^{2}=.010\right]$.

Figure-1

\section{Recognition of other-ethnicity faces}

\subsection{Method}

Having established that the DP and TD control groups were closely matched for visual experience with Black and East Asian faces, we next examined whether the Caucasian DPs showed impaired recognition of Black and East Asian faces. To do this, we used a sequential matching task (Figure 2). Trials began with a fixation cross $(750 \mathrm{~ms})$ followed by a target face presented in frontal view $(500 \mathrm{~ms})$. A mask constructed of high-contrast greyscale ovals was presented during an inter-stimulus-interval of 3000 ms. Following mask offset, a second test face was presented in $3 / 4$ view (i.e., rotated rightwards by $45^{\circ}$ from the point-of-view of the observer) for $500 \mathrm{~ms}$. Following the offset of the second face, participants were asked to judge whether the two faces presented were the same identity. Six practice trials were followed by 360 experimental trials; 120 for each face type, of which 60 presented different target and test identities. The experimental task was programmed in Matlab (Mathworks) using Psychtoolbox (Brainard, 1997; Pelli, 1997). 
Figure-2

Face stimuli were created using FaceGen Modeller Version 3.3 (Singular Inversions Inc.). All faces were male, of neutral facial expression, of the same age, and clean-shaven. Sixty facial identities were generated for each ethnicity, yielding 180 identities in total. The hairline was occluded in both the frontal and 3/4 exemplars of each identity. Stimuli subtended approximately $4.5^{\circ}$ of visual angle when viewed from $58 \mathrm{~cm}$. Each of the sixty faces within a face category appeared as a target face twice. The use of synthetic stimuli allowed precise control over lighting and orientation. Estimates of perceptual ability derived from a similar set of synthetic faces correlated closely with self-reported face recognition ability, and performance on complementary face tasks employing photographs of actors (Biotti et al., 2017).

In order to provide a fair comparison of SE and OE face recognition ability in the DPs and TD controls, we sought to equate the difficultly of SE and OE trials for typical Caucasian observers. The Black and East Asian faces were therefore made slightly more variable (the generation parameters were allowed to vary more widely) to counteract the OEE. Tasks where typical observers exhibit reduced accuracy for $\mathrm{OE}$ faces relative to SE faces may fail to detect group differences (DP < TD) in OE face identification because controls are closer to floor for OE faces. As a consequence, there is simply less scope to detect decrements associated with DP. However, where typical observers exhibit similar levels of accuracy for $\mathrm{SE}$ and $\mathrm{OE}$ faces there is equal scope to detect group differences for all face types ${ }^{3}$.

\subsection{Results}

\subsubsection{Group analyses}

The results were analysed using signal detection theory (Macmillan \& Creelman, 1991). A Same response following the presentation of a same-identity test stimulus was treated as a 'hit'. A Different response following the presentation of a same-identity test stimulus was treated as a 'false-alarm'. D-prime $\left(d^{\prime}\right)$ and Criterion $(C)$ statistics were calculated as measures of discrimination sensitivity and response bias, respectively. The distributions of $d^{\prime}$ (Figure 3a) and $C$ (Figure 3b) values were analysed using ANOVA with Face Type (Caucasian, Black, East Asian) as a within-subjects factor, and Group (DP, TD) as a betweensubjects factor. 
The analysis of discrimination sensitivity revealed a significant main effect of Group $[F(1,43)$ $\left.=6.242, p=.016, \eta_{\mathrm{p}}{ }^{2}=.127\right]$, whereby the DPs were less accurate than controls. We also observed a main effect of Face Type $\left[F(2,86)=13.619, p<.001, \eta_{\mathrm{p}}{ }^{2}=.241\right]$, whereby participants found the Black trials slightly easier than the Caucasian trials. Importantly, however, the Group $\times$ Face Type interaction revealed no evidence that DPs were disproportionately impaired on SE trials $\left[F(2,86)=1.526, p=.223, \eta_{\mathrm{p}}{ }^{2}=.034\right]$. Planned pairwise contrasts indicated that the DP group showed impaired discrimination of Caucasian $[t(43)=2.91, p=.006]$ and Black faces $[t(43)=2.418, p=.020]$. A similar trend was observed for East Asian faces, but the contrast did not reach significance $[t(43)=1.570, p=$ .124]. When the Black and East Asian trials were pooled to derive a combined measure of OE discrimination sensitivity, we found evidence of significant impairment in DP $[t(43)=2.173$, $p=.035]$. The criterion analysis revealed no main effect of Stimulus Type $[F(2,86)=1.431, p$ $\left.=.245, \eta_{\mathrm{p}}^{2}=.032\right]$, no main effect of Group $\left[F(1,43)=.395, p=.353, \eta_{\mathrm{p}}^{2}=.009\right]$, and no Group $\times$ Face Type interaction $\left[F(2,86)=.594, p=.554, \eta_{\mathrm{p}}^{2}=.014\right]$.

Figure-3

To ensure that the effects of Group revealed by the foregoing analyses were not attributable to a speed-accuracy trade-off, we also examined participants' reaction times (RTs). For the purposes of this analysis, responses longer than a participant's mean RT in a given condition +2.5 times their $S D$ for that condition were treated as outliers (criterion set prior to data analysis). On this basis, 284 (2.63\%) and 162 (3.00\%) observations were excluded for the TD and DP participants, respectively. The resulting distribution of RTs (Figure 3c) were analysed using ANOVA with Face Type (Caucasian, Black, East Asian) as a within-subjects factor, and Group (DP, TD) as a between-subjects factor. This analysis revealed no main effect of Face Type $\left[F(2,86)=.241, p=.787, \eta_{\mathrm{p}}^{2}=.006\right]$, no main effect of Group $[F(1,43)=.646, p$ $\left.=.426, \eta_{\mathrm{p}}{ }^{2}=.015\right]$, and no Group $\times$ Face Type interaction $\left[F(2,86)=1.980, p=.144, \eta_{\mathrm{p}}{ }^{2}=\right.$ $.044]$.

\subsubsection{Single-case analyses and correlations}

Single-case analyses of the DPs' discrimination ability $\left(d^{\prime}\right)$ revealed z-scores ranging from 2.757 to .135 for Caucasian faces (DP2 and DP9 had z-scores of less than -1.96). For Black faces, the DPs' z-scores ranged from -2.681 to .664 (DP3 and DP9 had z-scores of less than - 
1.96). For East Asian faces, the DPs' z-scores ranged -2.41 to 1.251 (only DP9 had a z-score of less than -1.96).

A high degree of correlation was seen between discrimination ability for Caucasian and East Asian faces in both the TD $(r=.785, p<.001)$ and DP groups $(r=.701, p<.001)$. A similar relationship was seen between discrimination ability for Caucasian and Black faces (TDs: $r=$ $.657, p<.001$; DPs: $r=.798, p<.001)$ and between discrimination ability for East Asian and Black faces (TDs: $r=.839, p<.001$; DPs: $r=.818, p<.001$ ).

Finally, to determine whether there were effects of visual experience, we examined whether discrimination accuracy for the three face types correlated with i) participants' scores on the nine subscales of the IECQ, and ii) summary measures derived from the subscales (i.e., total experience with Caucasian faces 0-18 years, total experience with Black faces 0-18 years, total experience with East Asian faces 0-18 years). These analyses revealed no significant relationships between visual experience and discrimination ability (all $r \mathrm{~s}<.25$, all $p \mathrm{~s}>.10$, all $N \mathrm{~s}=45)$.

\section{General Discussion}

The present study sought to establish whether the perceptual deficit seen in DP, diagnosed using SE faces, impairs the discrimination of OE faces. A sample of Caucasian DPs completed a sequential matching task, for three facial ethnicities - Caucasian, Black, and East Asian. Relative to Caucasian controls matched for experience with OE faces, the DPs were less accurate at discriminating both SE and OE faces, and we found no evidence of disproportionate impairment for SE faces. Given that the DPs and controls had similar opportunity to develop visual expertise for OE faces, these results indicate that DP impairs the visual processing of both SE and OE faces (see also DeGutis et al., 2011).

Some accounts of the OEE imply dissociation between the visual processing of SE and OE faces. For example, authors have argued that OE faces may engage a piecemeal analysis, while SE faces are processed as an integrated whole (Michel et al., 2006; Tanaka et al., 2004). Similarly, electrophysical markers (e.g., N170 and N250 ERP components) of face processing behave differently for SE and OE faces (Wiese et al., 2014). In contrast, our finding that DP impairs the discrimination of both SE and OE faces suggests that different 
facial ethnicities engage similar visual processing mechanisms; our results imply association not dissociation. This conclusion is also suggested by the individual differences seen in the typical population, where observers' relative ability to identify SE individuals, correlates closely with their relative ability to identify OE individuals (DeGutis et al., 2013; Wan et al., 2017). In addition, our results accord with recent evidence that individuals classified as 'super-recognisers' based on their SE face identification ability, out-perform SE controls at both SE and OE face matching (Bate et al., 2018).

Our results support the view that susceptibility to DP, and a lack of contact with OE faces, contribute independently to the poor recognition of OE faces (Esins et al., 2014; Wan et al., 2017). One possibility is that different face types (e.g., Caucasian, Black, East Asian) are processed by common neurocognitive mechanisms (Duchaine \& Yovel, 2015; Freiwald, Duchaine, \& Yovel, 2016; Haxby, Hoffman, \& Gobbini, 2000). In DP, atypical development of this system may lead to problems encoding faces and retaining face percepts, that affect all face types. In contrast, the OEE may reflect the fact that the parameters of this system become optimised for SE faces through experience. If correct, this view implies that authors should be careful not to conflate perceptual problems arising from DP from those arising from a lack of visual experience; for example, it may be misleading to characterise the OEE as "face-blindness" for OE faces (e.g., Wan et al., 2017).

The putative roles for i) inherited susceptibility to DP and ii) visual experience of OE faces suggested above can be illustrated with reference to the face-space framework, whereby individual faces are thought to be encoded as mean-relative vectors within a multidimensional space (Valentine, 1991). It has been hypothesised that typical observers raised in environments where most faces are SE, may develop a face-space dimensionality that is optimised to describe the variability in SE faces. The OEEs seen in otherwise typical observers may therefore reflect the fact that SE faces are represented with a greater resolution within face-space, compared to OE faces (e.g., Furl, Phillips, \& O'Toole, 2002; Valentine, 1991). Consistent with this view, periods of psychophysical adaptation to a particular facetype (e.g., East Asian or Caucasian faces) appear to re-calibrate face-space representations, aiding discrimination of the adapted category (Rhodes, Watson, Jeffery, \& Clifford, 2010). In contrast, DP may be a condition that fundamentally impairs the mean-relative representation of all face types within face-space. Consistent with this view, individuals with DP not only exhibit problems forming perceptual descriptions of faces (Biotti, Gray, \& Cook, 2018) but 
also exhibit atypical perceptual aftereffects for SE faces (Palermo, Rivolta, Wilson, \& Jeffery, 2011).

Consistent with previous findings (DeGutis et al., 2013; Wan et al., 2017), we found a close relationship between i) discrimination accuracy for East Asian faces and Caucasian faces, ii) discrimination accuracy for East Asian faces and Black faces, and iii) discrimination accuracy for Black faces and Caucasian faces. These results suggest that the three face types recruit similar processing mechanisms. In our paradigm, however, the Black face condition revealed perceptual deficits (DP < TD) more clearly than the East Asian face condition. When we restricted our analysis to the East Asian trials only, the effect of Group did not reach significance. The reason for this is unclear. We note, however, that a significant correlation was seen between PI20 scores - a measure of prosopagnosic traits - and discrimination accuracy for East Asian faces $(N=45, r=-.355, p=.017)$. This relationship provides some evidence that DP impairs the perception of East Asian faces in Caucasian observers.

It is well-established that a lack of contact with OE faces during development can lead to problems recognising OE faces - namely, the OEE (Sangrigoli et al., 2005; Wan et al., 2017; Wan et al., 2015). However, we found no correlation between scores on the IECQ - a measure of $\mathrm{OE}$ face experience - and observers' ability to discriminate OE faces. This lack of correlation should not be taken as evidence that experience does not influence the visual processing of $\mathrm{OE}$ faces. In the present experiment, we used typical controls with relatively limited experience of OE faces thereby ensuring a close match with the DP sample. This design choice suppressed the variability in $\mathrm{OE}$ face experience within the combined sample. The resulting lack of range in the experience measures likely hindered our ability to detect the influence of visual experience.

In summary, relative to typical controls closely matched for experience of OE faces, our sample of DPs were less accurate at discriminating OE faces. The fact that DP impairs the discrimination of both SE and OE faces suggests that these different types of face engage similar visual processing mechanisms. Our results support the view that susceptibility to DP, and a lack of contact with $\mathrm{OE}$ faces, contribute independently to the poor recognition of $\mathrm{OE}$ faces. 


\section{Footnotes}

${ }^{1}$ We use the term developmental prosopagnosia instead of congenital prosopagnosia to indicate the possibility that in some cases the disorder may appear during development and not necessarily from birth.

${ }^{2}$ Although we refer to our questionnaire as a 'contact' measure, several of the items refer to situations where individuation is required (e.g., "Most days, I had face-to-face interactions with (ethnicity) people" or "Most days, I encountered peers with (ethnicity) faces in educational or social contexts").

${ }^{3}$ In a similar vein, the fact that TD observers are closer to floor for inverted faces may explain why studies often find clear group differences between DPs and controls for upright faces, but not inverted faces (Klargaard, Starrfelt, \& Gerlach, 2018). 


\section{Acknowledgements}

ZC and FB were supported by a doctoral studentship awarded by City, University of London.

RC is supported by a Starting Grant awarded by the European Research Council (ERC-2016StG-715824). 


\section{References}

Avidan, G., Tanzer, M., \& Behrmann, M. (2011). Impaired holistic processing in congenital prosopagnosia. Neuropsychologia, 49(9), 2541-2552.

Bate, S., Bennetts, R., Hasshim, N., Portch, E., Murray, E., Burns, E., \& Dudfield, G. (2018).

The limits of super recognition: An other-ethnicity effect in individuals with extraordinary face recognition skills. Journal of Experimental Psychology: Human Perception and Performance.

Behrmann, M., \& Avidan, G. (2005). Congenital prosopagnosia: face-blind from birth. Trends in Cognitive Sciences, 9(4), 180-187.

Biotti, F., \& Cook, R. (2016). Impaired perception of facial emotion in developmental prosopagnosia. Cortex, 81, 126-136.

Biotti, F., Gray, K. L. H., \& Cook, R. (2017). Impaired body perception in developmental prosopagnosia. Cortex, 93, 41-49.

Biotti, F., Gray, K. L. H., \& Cook, R. (2018). Is developmental prosopagnosia best characterised as an apperceptive or mnemonic condition? Neuropsychologia, 124, 285-298.

Bowles, D. C., McKone, E., Dawel, A., Duchaine, B., Palermo, R., Schmalzl, L., . . Yovel, G. (2009). Diagnosing prosopagnosia: effects of ageing, sex, and participant-stimulus ethnic match on the Cambridge Face Memory Test and Cambridge Face Perception Test. Cognitive Neuropsychology, 26(5), 423-455.

Brainard, D. H. (1997). The psychophysics toolbox. Spatial Vision, 10(4), 433-436.

Cloutier, J., Li, T., \& Correll, J. (2014). The impact of childhood experience on amygdala response to perceptually familiar black and white faces. Journal of Cognitive Neuroscience, 26(9), 1992-2004.

Cook, R., \& Biotti, F. (2016). Developmental prosopagnosia. Current Biology, 26(8), R312R313.

Dalrymple, K. A., \& Palermo, R. (2016). Guidelines for studying developmental prosopagnosia in adults and children. Wiley Interdisciplinary Reviews: Cognitive Science, 7(1), 73-87.

DeGutis, J., Cohan, S., \& Nakayama, K. (2014). Holistic face training enhances face processing in developmental prosopagnosia. Brain, 137(Pt 6), 1781-1798.

DeGutis, J., DeNicola, C., Zink, T., McGlinchey, R., \& Milberg, W. (2011). Training with own-race faces can improve processing of other-race faces: evidence from developmental prosopagnosia. Neuropsychologia, 49(9), 2505-2513.

DeGutis, J., Mercado, R. J., Wilmer, J., \& Rosenblatt, A. (2013). Individual differences in holistic processing predict the own-race advantage in recognition memory. PLoS One, $8, \mathrm{e} 58253$. 
Duchaine, B., Germine, L., \& Nakayama, K. (2007). Family resemblance: ten family members with prosopagnosia and within-class object agnosia. Cognitive Neuropsychology, 24(4), 419-430.

Duchaine, B., \& Nakayama, K. (2006a). The Cambridge Face Memory Test: results for neurologically intact individuals and an investigation of its validity using inverted face stimuli and prosopagnosic participants. Neuropsychologia, 44, 576-585.

Duchaine, B., \& Nakayama, K. (2006b). Developmental prosopagnosia: a window to contentspecific face processing. Current Opinion in Neurobiology, 16, 166-173.

Duchaine, B., \& Yovel, G. (2015). A Revised Neural Framework for Face Processing. Annual Review of Vision Science, 1, 393-416.

Esins, J., Schultz, J., Wallraven, C., \& Bülthoff, I. (2014). Do congenital prosopagnosia and the other-race effect affect the same face recognition mechanisms? Frontiers in Human Neuroscience, 8, 759.

Freiwald, W., Duchaine, B., \& Yovel, G. (2016). Face Processing Systems: From Neurons to Real-World Social Perception. Annual Review of Neuroscience, 39, 325-346.

Furl, N., Phillips, P. J., \& O'Toole, A. J. (2002). Face recognition algorithms and the otherrace effect: computational mechanisms for a developmental contact hypothesis. Cognitive Science, 26(6), 797-815.

Geldart, S., Mondloch, C. J., Maurer, D., De Schonen, S., \& Brent, H. P. (2002). The effect of early visual deprivation on the development of face processing. Developmental Science, 5(4), 490-501.

Gerlach, C., Klargaard, S. K., Petersen, A., \& Starrfelt, R. (2017). Delayed processing of global shape information in developmental prosopagnosia. PLoS One, 12(12), e0189253.

Geskin, J., \& Behrmann, M. (2017). Congenital prosopagnosia without object agnosia? A literature review. Cognitive Neuropsychology, 22, 1-51.

Gray, K. L. H., Bird, G., \& Cook, R. (2017). Robust associations between the 20-item prosopagnosia index and the Cambridge Face Memory Test in the general population. Royal Society Open Science, 4(3), 160923.

Haxby, J. V., Hoffman, E. A., \& Gobbini, M. I. (2000). The distributed human neural system for face perception. Trends in Cognitive Sciences, 4(6), 223-233.

Jaquet, E., Rhodes, G., \& Hayward, W. G. (2008). Race-contingent aftereffects suggest distinct perceptual norms for different race faces. Visual Cognition, 16(6), 734-753.

Johnen, A., Schmukle, S. C., Hüttenbrink, J., Kischka, C., Kennerknecht, I., \& Dobel, C. (2014). A family at risk: Congenital prosopagnosia, poor face recognition and visuoperceptual deficits within one family. Neuropsychologia, 58, 52-63. 
Kennerknecht, I., Grüter, T., Welling, B., Wentzek, S., Horst, J., Edwards, S., \& Grüter, M. (2006). First report of prevalence of non-syndromic hereditary prosopagnosia (HPA). American Journal of Medical Genetics, 140A(15), 1617-1622.

Kennerknecht, I., Ho, N. Y., \& Wong, V. C. N. (2008). Prevalence of heriditary prosopagonsia (HPA) in Hong Kong Chinese population. American Journal of Medical Genetics, 146A(22), 2863-2870.

Klargaard, S. K., Starrfelt, R., \& Gerlach, C. (2018). Inversion effects for faces and objects in developmental prosopagnosia: A case series analysis. Neuropsychologia, 113, 52-60.

Macmillan, N. A., \& Creelman, C. D. (1991). Detection Theory: A User's Guide. New York, NY: Cambridge University Press.

McConachie, H. R. (1976). Developmental prosopagnosia. A single case report. Cortex, 12(1), 76-82.

McKone, E., Wan, L., Robbins, R., Crookes, K., \& Liu, J. (2017). Diagnosing prosopagnosia in East Asian individuals: Norms for the Cambridge Face Memory Test-Chinese. Cognitive Neuropsychology, 34(5), 253-268.

Michel, C., Rossion, B., Han, J., Chung, C. S., \& Caldara, R. (2006). Holistic processing is finely tuned for faces of one's own race. Psychological Science, 17(7), 608-615.

Palermo, R., Rivolta, D., Wilson, C. E., \& Jeffery, L. (2011). Adaptive face space coding in congenital prosopagnosia: typical figural aftereffects but abnormal identity aftereffects. Neuropsychologia, 49(14), 3801-3812.

Palermo, R., Willis, M. L., Rivolta, D., McKone, E., Wilson, C. E., \& Calder, A. J. (2011). Impaired holistic coding of facial expression and facial identity in congenital prosopagnosia. Neuropsychologia, 49(5), 1226-1235.

Pelli, D. G. (1997). The VideoToolbox software for visual psychophysics: transforming numbers into movies. Spatial Vision, 10(4), 437-442.

Rhodes, G., Watson, T. L., Jeffery, L., \& Clifford, C. W. G. (2010). Perceptual adaptation helps us identify faces. Vision Research, 50(10), 963-968.

Rossion, B. (2013). The composite face illusion: A whole window into our understanding of holistic face perception. Visual Cognition, 21(2), 139-253.

Sangrigoli, S., Pallier, C., Argenti, A. M., Ventureyra, V. A., \& de Schonen, S. (2005). Reversibility of the other-race effect in face recognition during childhood. Psychological Science, 16(6), 440-444.

Schmalzl, L., Palermo, R., \& Coltheart, M. (2008). Cognitive heterogeneity in genetically based prosopagnosia: a family study. Journal of Neuropsychology, 2(1), 99-117.

Shah, P., Gaule, A., Gaigg, S. B., Bird, G., \& Cook, R. (2015). Probing short-term face memory in developmental prosopagnosia. Cortex, 64, 115-122. 
Shah, P., Gaule, A., Sowden, S., Bird, G., \& Cook, R. (2015). The 20-item prosopagnosia index (PI20): a self-report instrument for identifying developmental prosopagnosia. Royal Society Open Science, 2(6), 140343.

Susilo, T., \& Duchaine, B. (2013). Advances in developmental prosopagnosia research. Current Opinion in Neurobiology, 23, 423-429.

Tanaka, J. W., \& Farah, M. J. (1993). Parts and wholes in face recognition. Quarterly Journal of Experimental Psychology, 46(2), 225-245.

Tanaka, J. W., Heptonstall, B., \& Hagen, S. (2013). Perceptual expertise and the plasticity of other-race face recognition. Visual Cognition, 21(9-10), 1183-1201.

Tanaka, J. W., Kiefer, M., \& Bukach, C. M. (2004). A holistic account of the own-race effect in face recognition: evidence from a cross-cultural study. Cognition, 93(1), 1-9.

Tanzer, M., Freud, E., Ganel, T., \& Avidan, G. (2013). General-holistic impairment in congenital prosopagnosia: Evidence from Garner's speeded-classification task. Cognitive Neuropsychology, 30(6), 429-445.

Valentine, T. (1991). A unified account of the effects of distinctiveness, inversion, and race in face recognition. Quarterly Journal of Experimental Psychology, 43(2), 161-204.

Wan, L., Crookes, K., Dawel, A., Pidcock, M., Hall, A., \& McKone, E. (2017). Face-blind for other-race faces: Individual differences in other-race recognition impairments. Journal of Experimental Psychology: General, 146(1), 102-122.

Wan, L., Crookes, K., Reynolds, K. J., Irons, J. L., \& McKone, E. (2015). A cultural setting where the other-race effect on face recognition has no social-motivational component and derives entirely from lifetime perceptual experience. Cognition, 144, 91-115.

Wiese, H., Kaufmann, J. M., \& Schweinberger, S. R. (2014). The neural signature of the own-race bias: evidence from event-related potentials. Cerebral Cortex, 24(3), 826835. 


\section{Figure 1}
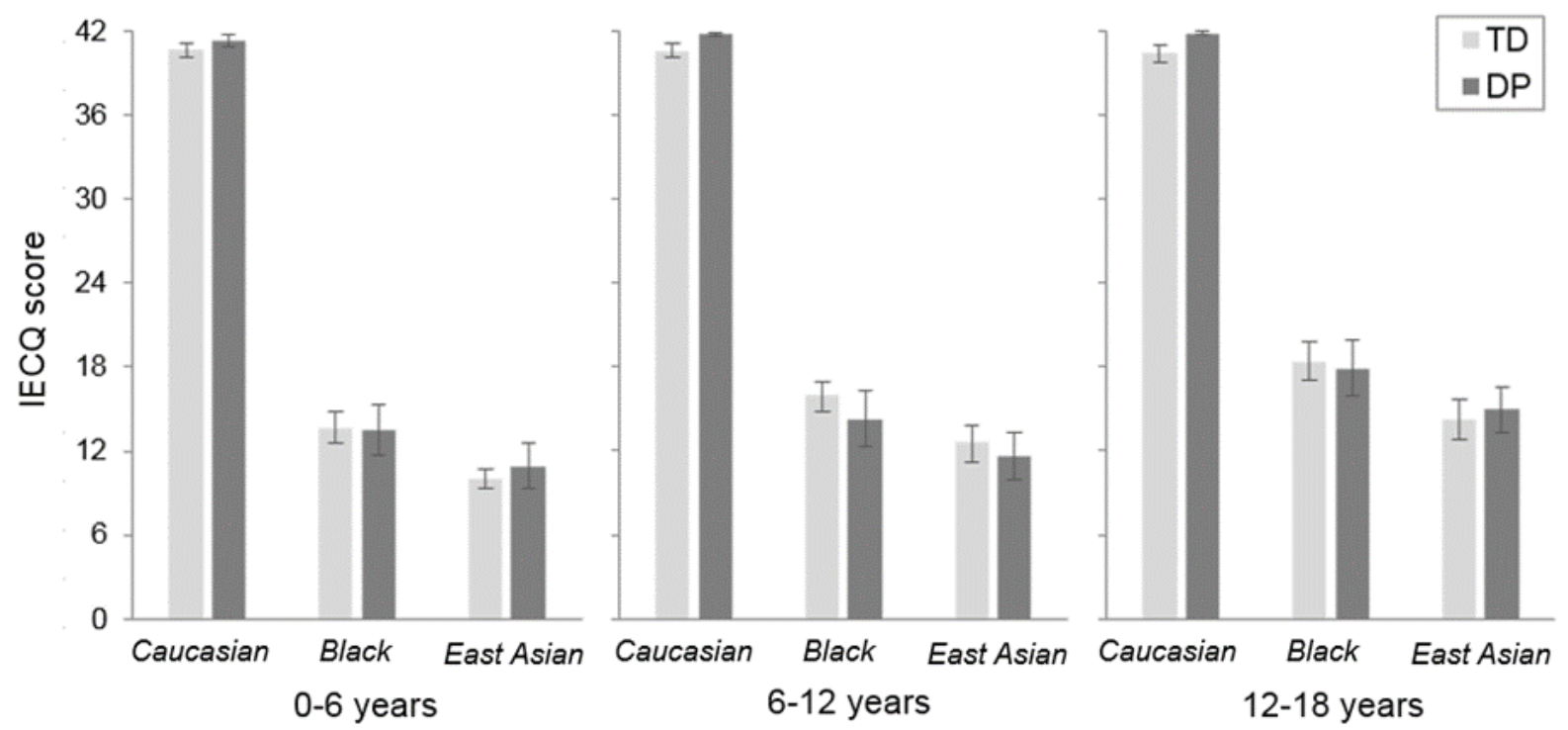

Figure 1: The TD and DP groups produced very similar responses to the Inter-Ethnicity Contact Questionnaire (IECQ), indicating that they had equal opportunities to develop perceptual expertise for Black and East Asian faces. Error bars denote \pm 1 SEM. 
Figure 2

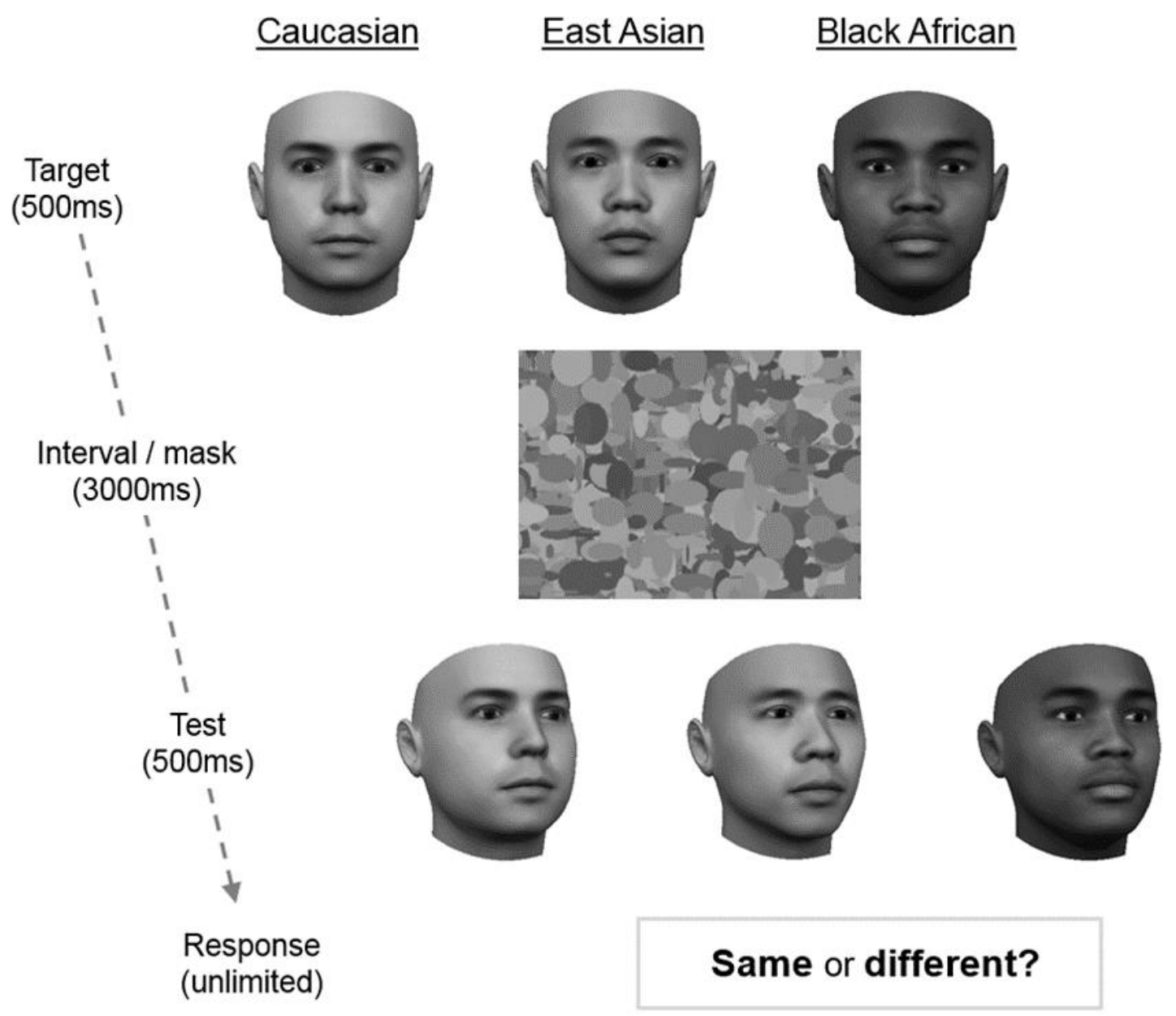

Figure 2: The procedure used in the sequential matching task. 


\section{Figure 3}

(a)

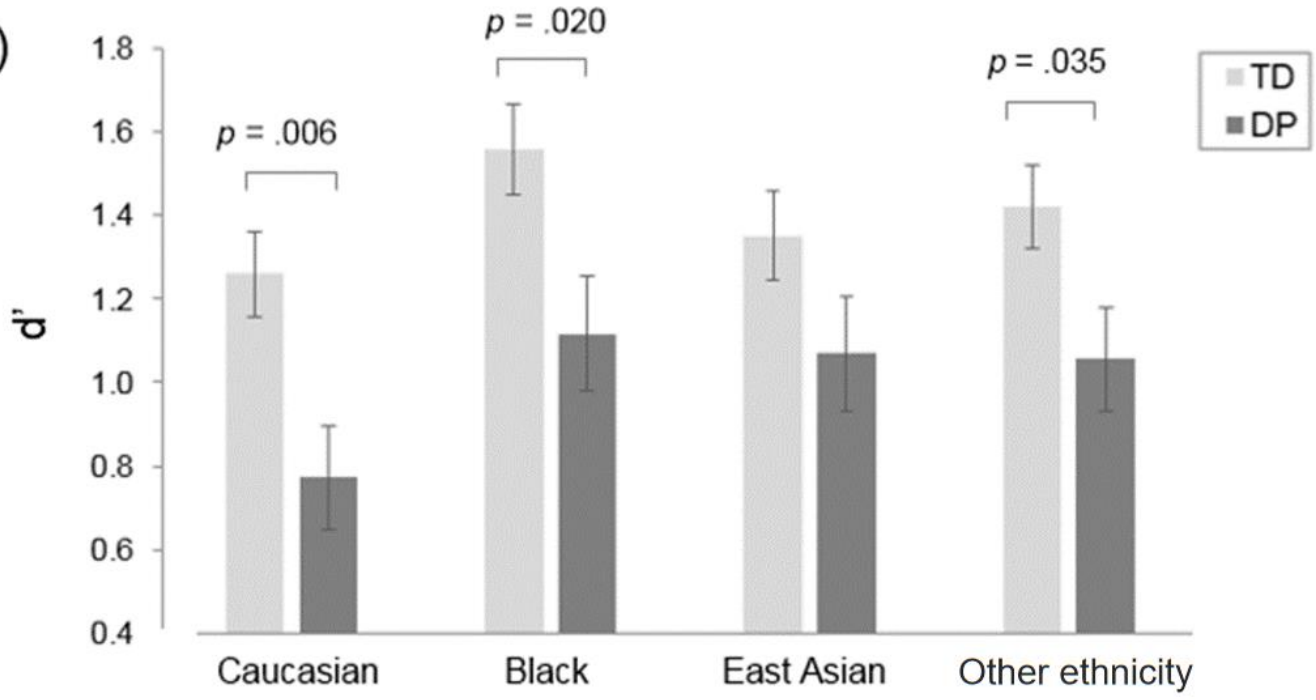

(b)

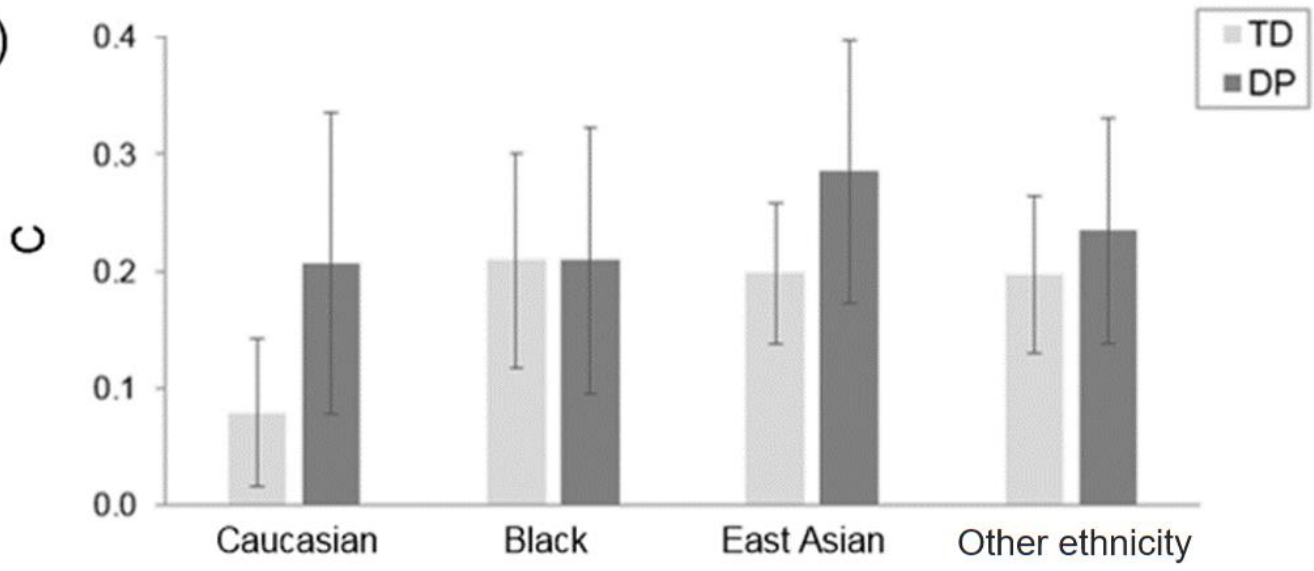

(c)

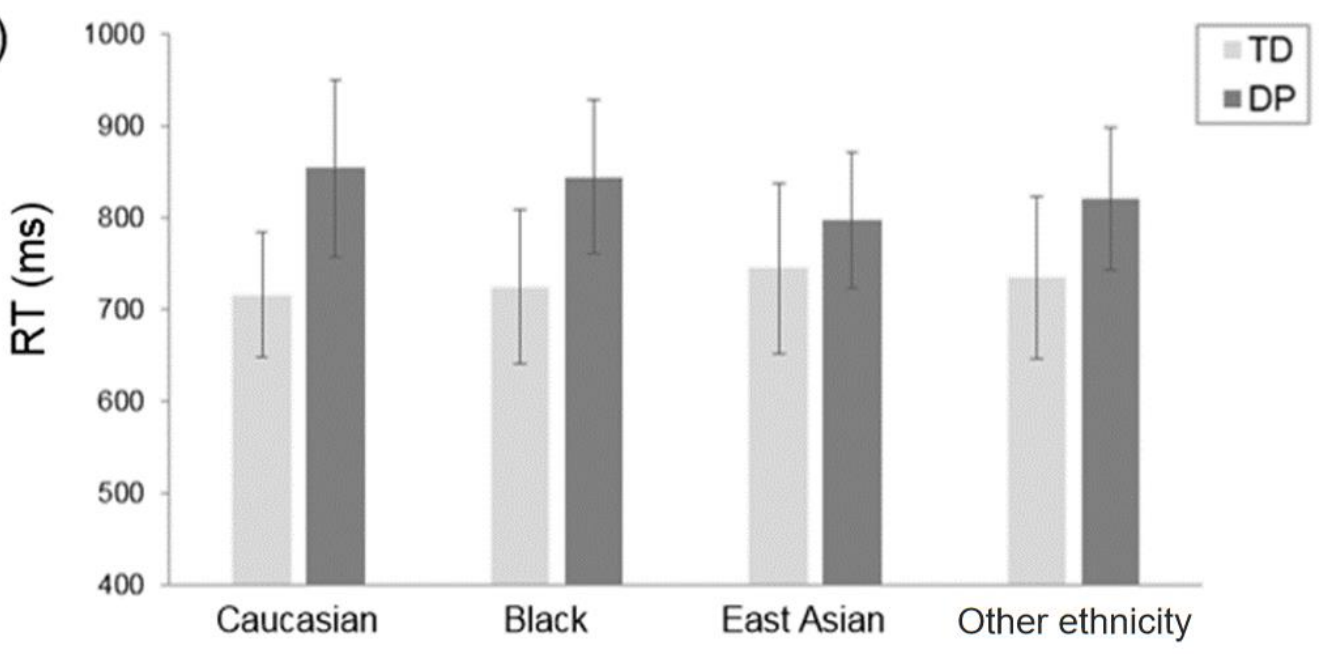

Figure 3: (a) The distribution of discrimination sensitivity statistics $\left(d^{\prime}\right)$ for the typically developed controls (TDs) and the developmental prosopagnosics (DPs). (b) The distribution of criterion statistics $(C)$ for the TDs and the DPs. (c) The distribution of reaction times (RTs) for the TDs and the DPs. Error bars denote \pm 1 SEM. 


\section{Table 1}

Table 1: The scores of each DP on the 20-Item Prosopagnosia Index (PI20); the Cambridge Face Memory Test (CFMT); and the Cambridge Face Perception Test (CFPT).

\begin{tabular}{|c|c|c|c|c|c|c|c|c|}
\hline Participant & Sex & Age & PI20 & $\begin{array}{c}\text { CFMT } \\
(\%)\end{array}$ & $\begin{array}{c}\text { CFPT } \\
\text { (Errors) }\end{array}$ & zPI20 & zCFMT & zCFPT \\
\hline DP1 & $\mathrm{F}$ & 42 & 76 & 59.72 & 52 & -4.19 & -2.83 & -2.42 \\
\hline DP2 & M & 37 & 77 & 40.28 & 44 & -4.30 & -5.01 & -1.56 \\
\hline DP3 & $\mathrm{F}$ & 54 & 85 & 45.83 & 74 & -5.18 & -4.39 & -4.77 \\
\hline DP4 & F & 44 & 92 & 45.83 & 62 & -5.95 & -4.39 & -3.49 \\
\hline DP5 & $\mathrm{F}$ & 41 & 84 & 40.28 & 40 & -5.07 & -5.01 & -1.13 \\
\hline DP6 & $\mathrm{F}$ & 46 & 76 & 58.33 & 36 & -4.19 & -2.99 & -0.70 \\
\hline DP7 & $\mathrm{F}$ & 28 & 78 & 62.50 & 36 & -4.41 & -2.52 & -0.70 \\
\hline DP8 & $\mathrm{M}$ & 38 & 78 & 63.89 & 40 & -4.41 & -2.36 & -1.13 \\
\hline DP9 & M & 23 & 83 & 34.72 & 68 & -4.96 & -5.63 & -4.13 \\
\hline DP10 & $\mathrm{F}$ & 38 & 82 & 48.61 & 74 & -4.85 & -4.08 & -4.77 \\
\hline DP11 & $\mathrm{F}$ & 38 & 78 & 54.17 & 28 & -4.41 & -3.45 & 0.15 \\
\hline DP12 & M & 52 & 76 & 55.56 & 54 & -4.19 & -3.30 & -2.63 \\
\hline DP13 & $\mathrm{F}$ & 33 & 74 & 58.33 & 58 & -3.97 & -2.99 & -3.06 \\
\hline DP14 & $\mathrm{F}$ & 38 & 82 & 48.61 & 64 & -4.85 & -4.08 & -3.70 \\
\hline DP15 & M & 61 & 92 & 58.33 & 40 & -5.95 & -2.99 & -1.13 \\
\hline DP mean & & 40.87 & 80.87 & 51.67 & 51.33 & & & \\
\hline (SD) & & $(9.76)$ & $(5.60)$ & $(8.94)$ & (14.85) & & & \\
\hline Comparison mean & & 39.20 & 37.96 & 84.98 & 29.41 & & & \\
\hline$(\mathrm{SD})$ & & (13.36) & (9.08) & $(8.92)$ & $(9.35)$ & & & \\
\hline
\end{tabular}

Note: For the purposes of the z-score analyses, the scores of the DPs were evaluated against a comparison sample of 54 observers ( 23 males) who completed these diagnostic tasks in return for a small honorarium, under the same conditions as the DPs (i.e., tested in person, under controlled lab conditions). 